\title{
Using two languages to inform and inspire: a case study using bilingual digital technology to educate healthcare students demonstrating the importance of language choice in enhancing communication and patient care in Wales
}

\author{
Beryl Cooledge \\ Bangor University, UK \\ Peggy Murphy \\ Bangor University, UK
}

\section{Abstract}

Welsh is the indigenous language of Wales, the Welsh Language (Wales) Measure (2011) means that English and Welsh have equal parity in Wales. Many nursing students are now embarking on their studies having completed their formal education throughout the medium of Welsh and thus feel more comfortable studying in their mother tongue. Therefore, Bangor University aims to teach Welsh speakers alongside English speakers and offers a choice to their students so they can study in their preferred language. This case study examines how a bilingual ethos can be incorporated to provide a dynamic approach to teaching using pre-recorded lectures and innovative group work. Presentations are recorded in two different languages and are supported by a gapped handbook, ensuring that students focus on the most important aspects of the lecture. The pre-recorded lecture capture is available for students to access after the lecture to reinforce the learning. Crossover group work (Mortiboys, 2010) was included to ensure that each member of the class contributed to discussions and fully understood the topic of managing pain in various scenarios.

This resulted in a stimulating session which increased students' motivation and fostered ownership and interest in digital technology, but at the same time met the language and educational needs of a diverse population of students.

Keywords: active offer; inclusive practice; innovative approaches in nurse education; teaching bilingually; blended learning. 


\section{Introduction}

In recognition that Welsh is the indigenous language of Wales, the Welsh Language (Wales) Measure (2011) protects the language and ensures that English and Welsh have equal status in Wales. In order to support all higher education provision in the medium of Welsh, the Coleg Cymraeg Cenedlaethol (CCC) (http://www.colegcymraeg.ac.uk) was established. This is a centrally governed body which promotes, maintains, and develops Welsh higher education provision in Wales. The CCC aims to enrich, deepen and broaden Welsh provision, alongside stimulating and responding to the needs of students studying through the medium of Welsh. In order to provide inclusive education and to recognise that some students feel more comfortable engaging with their studies through the medium of Welsh, universities operating in Wales have an obligation to meet Welsh speaking students' needs. The university in this case study has a bilingual ethos, giving students the opportunity to study in their language of choice. This approach is in line with the Bangor University's School of Healthcare Science's ethos which aims to ensure that programmes of study are cultural and linguistically sensitive. In practice this means that Welsh and nonWelsh speakers are taught side by side (Roberts et al., 2010). Teaching bilingually has unique challenges, in order to meet these an innovative approach was designed to increase student interaction and address language diversity. This approach recognised how learning development could be stimulated using digital technologies. This is a case study of a session on pain management that was designed for English and Welsh speaking level 5 , second year undergraduate pre-registration adult nursing students.

\section{Background}

Inclusive approaches in higher education are encouraged by the Higher Education Academy (HEA, 2011). The UK Professional Standards Framework for Higher Education (HEA, 2011) advocates that effective teaching and learning needs to be student centred. Nursing students have diverse learning styles and often have to juggle the demands of work, life and family in addition to their studies (Bednarz et al., 2010). This highlights the need for a more flexible approach to teaching which is required when teaching in one language but is further complicated in Wales with two official languages. Welsh is the indigenous (albeit minority) language spoken in Wales (Thomas, 1994). For nursing students studying in Wales it is important that they can access learning resources in their 
preferred language (Welsh Government, 2016). In nursing, communication is an essential skill so it is vitally important that student nurses are aware of the language needs of the population they aim to serve (Welsh Government, 2016).

The need for communicating in one's first language is heightened in times of stress; when people become ill they often find it easier to express themselves in their mother tongue and healthcare practitioners need to understand this (Thomas, 1994). Previously, as most Welsh speakers are bilingual, it was assumed that it was acceptable to offer care in the medium of English. The publication of the Welsh Government (WG) policy More than Words (2016) highlighted that for many Welsh speakers, being able to use their own language is central to their needs and a core component of care (WG, 2016). This philosophy underpins the need for the 'Active Offer' (WG, 2016) principle. The 'Active Offer' in Wales puts the onus on the healthcare practitioner to ask patients their preferred language rather than leaving it to vulnerable patients to request. There is therefore a need for healthcare practitioners to adopt sensitivity and conscious awareness of how language (Irvine et al., 2006) impacts upon the quality of patients' care. This is also a statutory requirement of the Welsh Language (Wales) Measure (2011) and any healthcare professionals who choose to work in Wales are required to provide an active offer to patients they care for. Welsh language schemes involve the provision of services to the public in Wales (WG, 2016) to ensure that organisations such as NHS Wales are committed to providing culturally and linguistically sensitive person-centred care. The rationale and description of the case study will now be discussed.

\section{Methodology}

The design was based upon Race's (2007) 'ripples on a pond' model of learning which suggests that experiential learning is an interactive whole rather than sequential cycle. Race (2007) advocates that 'needing and wanting' to learn is at the centre of learning, causing ripples of motivation to send the student through doing, digesting and feedback stages. The case study used a blended approach including lecture capture (Panopto), in English and Welsh. Lecture capture is a voice recording of the lecture alongside the power point slides that students can access at a suitable time from any mobile device or computer. 
The students were directed to watch the recorded lecture in their chosen language prior to attending the session. Recording the lectures in English and Welsh role modelled respect for individual language needs. This part of the case study was in keeping with a blended approach which is defined by Smith (2001, cited Ireland et al., 2009, p.124) as 'a method of educating at a distance that uses technology (high tech such as the internet combined with the traditional 'stand up education')'. As the students accessed the lecture capture via the Visual Learning Environment (Blackboard), this enabled the tutor to monitor whether students had accessed the recorded lecture; although knowing that a student has accessed a resource does not necessarily mean that they have interacted with it, or understood it (Jokinen and Mikkonen, 2013), just as recording students attending lectures does not equate to measuring whether they have absorbed the content (Race, 2016). What Petrides (2002) found was that when educators designed learning experiences using a blended approach, it encouraged deeper learning due to increased learner engagement.

The contact time was designed so that when students arrived in the classroom an interactive workbook was used as a resource to promote discussion and evaluate students' learning of the pre-recorded lecture. It consisted of a series of questions which focused on the key elements about pain, as Hughes and Quinn (2013) state traditional lectures over rely on simply the transmission of information. Offering a combination of recorded lecture and interactive workbook (in the students' preferred language) addressed the 'comprehension' level of Bloom's taxonomy which encouraged deeper learning (Bloom 1956, cited Wilkie and Burns, 2003, p.34).

In nurse education, $50 \%$ of the programme is set in clinical practice; student nurses are encouraged to learn by doing (Nursing and Midwifery Council, 2011). Students are constantly being challenged to apply evidence-based theory to practice. Learning by doing was mirrored in the interactive workbook. Students learn in both in university and in practice as part of a team as it is a professional requirement that nurses work collaboratively (Nursing and Midwifery Council, 2015). The students were asked to work in groups to complete the workbook, thereby promoting a team approach to problem-solving.

The constructivist approach to learning advocates that learning should be placed in a rich context, reflecting the real world of nursing. Students learn more effectively if the information is presented through concrete hands-on examples and this was incorporated in the session described here. In the second half of the three hour session, the students 
were involved in group work examining a range of real life scenarios that they might encounter in clinical practice and asked to discuss the nursing care and pain relief management in each case. For example, one scenario involved a woman suffering pain after an operation; another involved a young man sustaining a sporting injury.

The crossover or jigsaw method of grouping students was implemented as devised by Mortiboys (2010). This involved the learners being divided into groups of five and each group given a different scenario to discuss. Students were required to apply the information obtained from the pre-recorded lecture to plan nursing care and pain relief under supervision from the lecturer. Each member of the group needed to understand and write down a summary of the care they had discussed. The task had two stages; in the second stage new groups were formed with one person from each of the original groups making up the new group. In the new group, each member had to feedback the scenario and conclusions from their first group. This activity was chosen as it ensured that every student participated. It meant that the learner was required to 'read, discuss, teach and listen en route to learning about six case studies' (Mortiboys, 2010, no pagination).

\section{Evaluation}

Meeting the language requirements of the students along with the growth in information and communication technology led to designing engaging materials to promote active learning. Additionally it improved students' experience with digital technology. This was delivered in a way that was learner-centred, flexible and accessible for the diverse student nurse of today. Inclusivity and widening participation were somewhat addressed by prerecording lectures in Welsh and English. The session plan required students to access the recorded lecture beforehand, not all students participated in this activity. This led to those students being more dependent upon the peers that had engaged. Answers to the gapped handbook were discussed on completion, which provided students with immediate feedback. The pre-recorded version of the lecture was available for students to refer to after the session and many of them reported later that they had found these useful to review and revise the lecture at their leisure, thereby achieving the goal of guiding the students and increasing their confidence to use digital technology. 
The Welsh Assembly Government (2009) recognises that higher education should equip individuals, whatever their background, with the knowledge, skills and attributes to achieve maximum intellectual and personal fulfilment. Inclusive practice requires lecturers to minimise any barriers that students face with accessing the curriculum (Craig and Zinkiewicz, 2010). Designing this session was time consuming, but the benefits to the students' learning outweighed this because they appreciated an interactive, dynamic session. The learning experience was evaluated extremely well using a Likert scale.

McKimm and Jollie (2007) proposed that educators need to reflect upon their own teaching and learning practice and design resources that encourage collaborative practice and lifelong learning. The interactive workbook used alongside the recorded lecture enabled students to assess and evaluate their own learning with their peers. Radical social constructivism identifies learning as a social activity and this was the philosophy behind the idea of working in groups. Another use of the interactive workbook as a learning resource was that using a workbook reduced the need for note taking. It helped students to focus on the important information and avoided the wasteful process employed in many traditional lectures when students write down what is on the screen (Race, 2007).

The information technology was used as a facilitative tool, encouraging the student to be an active learner rather than a passive recipient (Petty, 2013). The session was evaluated using a five point Likert scale questionnaire. The questions were written to measure whether the session had met 'the areas of activity' and 'core knowledge' of the UK Professional Standards Framework (HEA, 2011). The session itself was designed to incorporate the professional values from the UK Professional Standards Framework (HEA, 2011), particularly focusing on value two, which is promoting participation in higher education and equality of opportunity for learners. In addition, informal comments from the students reflected the Likert scale, stating how much they had enjoyed the group work; and many reported that they had found the session interesting, enjoyable and that it stimulated their desire to learn more about the subject. A few had mentioned that they would like a longer session. 


\section{Figure 1. The following is a graph representing the responses to a Likert questionnaire.}

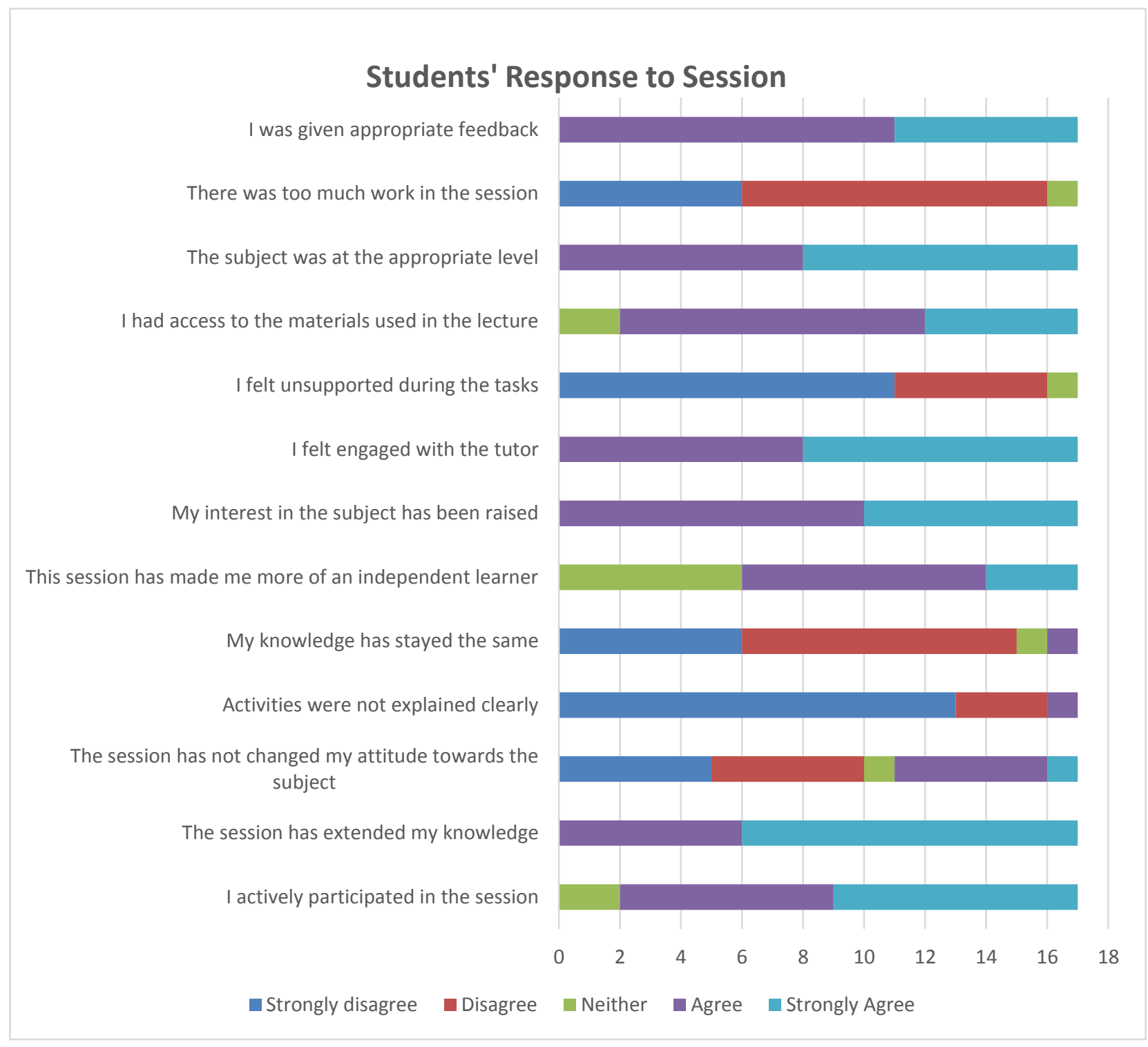

\section{Discussion}

The rationale for using digital technology to meet the language and educational needs of diverse students included the use of lecture capture. Lecture capture has now been used to digitally record information for some time, as Freed et al. (2014) report that it addresses limited resources, decreases lecturer workload and improves students' study. However, Freed et al. (2014) observed that there are mixed opinions regarding this. Many members of a nursing faculty in their qualitative study felt that lecture capture caused technostress, which is overload from technology, and in addition might encourage students' absence 
from class. Race (2016) advocates that lecture capture should be used sparingly as many lectures are less than dynamic, stating only some sections of some of his lectures are worthy of recording. Freed et al. (2014) suggest information technology skills and innovations in pedagogy should take different learning styles into account. The design of this case study used both high tech and low tech learning resources to address this.

The design of this session followed Vygotsky's (1962) notion that learning happens when there is an intersection between teachers designing structured activities that guide students' spontaneous learning through exploration. Some students required more guidance and support to overcome possible anxiety regarding accessing technology. The authors propose that more coaching is needed for some to gain gradual independence in order to ensure that all students can access online directed study. Reeves and Reeves (2013) report that there is a need to consider how older participants learn with technology. It is also noted that not all school leavers are confident with accessing technology either. Gulati (2006) recommended that information skills can be best developed when embedded in the learners' contexts and discipline. A major reason for the use of the interactive workbook was to assess student understanding and to emphasise the key points from the pre-recorded lecture. Using both of these approaches created more of a 'flipped classroom'. This was further developed by incorporating the findings of Strayer (2012) who established that in a flipped classroom, students were more likely to support each other but were more confused about what learning was expected of them. The authors advocate that as long as the students feel safe in the learning environment, some degree of confusion is often a part of the learning process. Using Vygotsky's (1962) principles, the workbook deliberately guided the students individually towards learning goals from the pre-recorded lecture. The session was designed so that students completed the workbook with peer support.

The rationale for using the crossover group work (Mortiboys, 2010) was that this activity ensured full participation and teamwork, not one person could opt out as everyone had to contribute and recall the discussions in the re-grouping. The design acknowledged that learner confidence is increased when activities endeavour that every member of the group learns (May and Thomas, 2010). Scenarios were set for students to resolve and were used to help students apply theoretical concepts to real life nursing practice, in order to bridge the theory to practice gap. As Wilkie and Burns (2003) note, students develop many skills through collaborative working. These skills include: interpersonal skills, tolerance, 
and respect for others' beliefs. All of these skills help to increase the employability of nursing students. This element of the design comes under the fourth and fifth level of Bloom's taxonomy of analysis and synthesis (Bloom 1956, cited Wilkie and Burns, 2003, p.34).

\section{Conclusion}

Planning lectures in a way that encouraged participation, by directing students to view the bilingual recorded lectures, embedded good practice in a number of ways. Firstly it encouraged the students to prepare their knowledge beforehand in order to treat this as a learning opportunity and to assess their own learning throughout the session. Secondly, nursing is a profession that has at its core the values of fairness, justice and respect for others. Promoting the dignity of others, and particularly their language choice, is paramount to the profession (NMC, 2015). This was integral to the session alongside teaching about pain. Thirdly, reports have observed that students are reluctant to engage with online environments (Jokinen and Mikkonen, 2013), therefore, using a blended learning approach encourages engagement with technology. Fourthly, nurses are required to keep up-to-date with their knowledge and skills (NMC, 2010): this was encouraged by increasing students' motivation and fostering ownership of knowledge rather than possessing information (Race, 2007). Lastly, as Petty (2013) remarks, the focus should be on guided learning rather than simply giving information for the learner to assimilate passively.

\section{References}

Bednarz, H., Schim, S. and Doorenbos, A. (2010) 'Cultural diversity in nursing education: perils, pitfalls and pearls', Journal of Nursing Education, 49(5), pp. 253-260.

Craig N. and Zinkiewicz, L. (2010) Inclusive practice within psychology. York: Higher Education Academy. 
Freed, P.E., Bertram, J.E. and McLaughlin, D.E. (2014) 'Using lecture capture: a qualitative study of nursing faculty's experience', Nurse Education Today, 34(4), p. 598-602.

Gulati, S. (2006) 'Application of new technologies: nurse education', in Glen, S. and Moule, P. (eds.) e-Learning in nursing. Nurse education in practice. Hampshire: Palgrave MacMillan Basingstoke, pp.20-38.

Higher Education Academy (2011) United Kingdom Professional Standards Framework: for teaching and supporting learning in higher education. Available at: https://www.heacademy.ac.uk/sites/default/files/downloads/ukpsf 2011 english.pdf (Accessed: 3 March 2017).

Hughes, S.J. and Quinn, F.M. (2013) Quinn's principles and practice of nurse education. $6^{\text {th }}$ edn. London: Cengage Learning.

Ireland, J., Martindale, S., Johnson, N., Adams, D., Eboh, W. and Mowatt, E. (2009) 'Blended learning in education: effects on knowledge and attitude', British Journal of Nursing, 18(2), pp. 124-130.

Irvine, F., Roberts, G., Jones, P., Spencer, L., Baker, C. and Williams, C. (2006) 'Communicative sensitivity in the bilingual healthcare setting: a qualitative study of language awareness', Journal of Advanced Nursing, 53(4), pp. 422-434.

Jokinen, P. and Mikkonen, I. (2013) 'Teachers' experience of teaching in a blended learning environment', Nurse Education in Practice, 13(6), pp. 524-528.

McKimm, J. and Jollie, C. (2007) Facilitating learning and teaching methods London: Deanery Project.

May, H. and Thomas, L. (2010) 'Promoting success for all through inclusive Learning and Teaching', Shaping the future: Higher Education Academy Annual Conference 2010. University of Hertfordshire, 22-23 June. 
Mortiboys A. (2010) How to be an effective teacher in higher education. Berkshire: Open University Press.

Nursing and Midwifery Council (NMC) (2010) Standards for pre-registration nursing education. Available at:

https://www.nmc.org.uk/globalassets/sitedocuments/standards/nmc-standards-forpre-registration-nursing-education.pdf (Accessed: 30 March 2017).

Nursing and Midwifery Council (NMC) (2015) The code: standards of conduct, performance and ethics for nurses and midwives. London: NMC.

Petrides, L.A. (2002) 'Web-based technologies for distributed (or distance) learning. Creating learner centred educational experience in the higher education classroom', International Journal of Instructional Media, 29(1), pp. 69-77.

Petty, J. (2013) 'Interactive, technology-enhanced self-regulated learning tools in healthcare education: a literature review', Nurse Education Today, 33(1), pp. 53-59.

Race, P. (2007) The lecturer's toolkit: a practical guide to assessment, learning and teaching. $3^{\text {rd }}$ edn. Abingdon: Routledge.

Race, P. (2016) Lecture capture versus lecture napture? Assessment, learning and teaching in higher education. Available at: http://phil-race.co.uk/lecture-captureversus-lecture-napture/ (Accessed: 3 March 2017).

Reeves, T.C and Reeves, P.M. (2013) 'Designing online and blended learning', in Hunt, L. and Chalmers, D. (eds.) University teaching in focus: a learning-centred approach. Oxon: Routledge, Chapter 7, pp. 112-127.

Roberts, G.W., Irvine, F.E., Tranter, S. and Spencer, L.H. (2010) 'Identifying priorities for establishing bilingual provision in nurse education: a scoping study', Nurse Education Today, 30(7), pp. 623-630. 
Strayer, J.F. (2012) 'How learning in an inverted classroom influences cooperation, innovation and task orientation', Learning Environments Research, 15(2), pp. 171 193.

Thomas, N. (1994) 'Welsh-speakers as a territorial linguistic minority in the European Union', in Williams, R.H., Williams, H. and Davies, E. (eds.) Social work and the welsh language. Cardiff: University of Wales Press, pp. 155-171.

Vygotsky, L. (1962) Thought and Language. Cambridge MA: Massachusetts Institute of Technology.

Welsh Assembly Government (2009) For our future - the 21st century higher education strategy and plan for Wales. Available at: http://gov.wales/topics/educationandskills/publications/guidance/forourfuture/?lang= en (Accessed: 3 March 2017).

Welsh Government (2016) More than words: strategic framework for Welsh language services in health, social services and social care. Cardiff: Welsh Government.

Welsh Language (Wales) Measure (2011) nawm1. Available at: www.legislation.gov.uk/mwa/2011/1/contents/enacted (Accessed: 28 March 2017).

Wilkie, K. and Burns, I. (2003) Problem-based learning: a handbook for nurses. Hampshire: Palgrave Macmillan Basingstoke.

\section{Author details}

Beryl Cooledge MA, RGN, FHEA, PGcert(HE), PGcert(FE), Adult Nurse Lecturer. Employed by the Coleg Cymraeg Cenedlaethol, with the primary role of supporting students studying through the medium of Welsh. Interested in improving person centred care through the education of future registered nurses.

Peggy Murphy RGN NTF 2014 SFHEA BA (Hons) PGCEL MSc, Nurse Lecturer and Educational Developer. Interested in helping student nurses learn how to learn and gain 
confidence in their own ability; peer learning self and peer assessment and how feedback and feedforward impact upon student learning. 